\title{
MATURITY-ASSOCIATED VARIATIONS IN ANTHROPOMETRY, PHYSICAL FITNESS, AND SPORT-SPECIFIC SKILLS AMONG YOUNG MALE AND FEMALE FUTSAL PLAYERS
}

original paper

() Wroclaw University of Health and Sport Sciences

DOI: https://doi.org/10.5114/hm.2022.108321

\section{MUSTAFA SÖĞÜT ${ }^{1 \oplus}$, HAKAN YAPICI ${ }^{2}$, LEONARDO G.O. LUZ ${ }^{3,4}$, BRUNO GIUDICELLI $^{3}$, FILIPE MANUEL CLEMENTE ${ }^{5}{ }^{\circledR}$, ALİ AHMET DOĞAN ${ }^{2}$}

${ }^{1}$ Department of Physical Education and Sports, Faculty of Education, Middle East Technical University, Ankara, Turkey

${ }^{2}$ Faculty of Sport Sciences, Kırıkkale University, Kırıkkale, Turkey

${ }^{3}$ Kinanthropometry, Physical Activity and Health Promotion Laboratory, Federal University of Alagoas, Arapiraca, Brazil

${ }^{4}$ Research Unit for Sport and Physical Activity, Faculty of Sport Sciences and Physical Education, University of Coimbra, Coimbra, Portugal

${ }^{5}$ Escola Superior Desporto e Lazer, Instituto Politécnico de Viana do Castelo, Viana do Castelo, Portugal

\begin{abstract}
Purpose. The aim of this study was to determine the maturity-related variations in anthropometry, physical fitness, and sport-specific skills among young male and female futsal players.

Methods. Overall, 77 athletes (44 boys and 33 girls) aged 10.5-13.7 (12.3 \pm 0.9) years were measured for stature, body mass, 2 skinfolds, as well as 3 fitness and 2 sport-specific test items.

Results. Compared with boys, girls were significantly more advanced in maturation and had greater body mass index and body fat percentage. Except for the countermovement jump result, boys outperformed girls in all fitness and sport-skill assessments. Regardless of gender, early maturing players were significantly taller and heavier and had higher body fat percentage and grip strength than their late maturing counterparts. In boys, none of the other physical fitness and sport-specific skill measures significantly differed between contrasting maturity groups. In turn, early maturing girls had significantly better scores in all physical fitness measurements than late maturing girls. Partial correlations, with chronological age controlled as a covariate, indicated moderate to high correlations between the maturation indicator and stature and body mass in both boys and girls. Except for grip strength and dribbling tests for boys and girls, respectively, other physical fitness and sport-specific skill measures did not show a significant correlation with maturity status.
\end{abstract}

Conclusions. These results highlight that rather than with functional and sport-specific characteristics, physical maturity status may be associated with greater body size in young futsal players.

Key words: biological maturation, functional capacities, futsal, physical growth

\section{Introduction}

Biological maturation is defined as the progress towards the biologically mature state [1]. It is a biological process that involves all bodily tissues, organs, and systems [2] and is influenced by various genetic and environmental factors [3]. Timing and tempo are $2 \mathrm{com}-$ ponents of maturation [4]. They refer to the time at which specific maturity-associated changes occur and the rate at which biological maturation progresses, respec- tively [5]. Thus, children of the same chronological age may vary in their maturational status [6, 7].

Earlier studies have documented the maturityrelated variations in morphological and functional characteristics of young athletes [8-11]. Additionally, several investigations reported significant associations between maturity status and actual performance such as ranking $[12,13]$. Depending on the specific characteristics and requirements of a sport, being late or advanced in maturation may be the key

Correspondence address: Mustafa Sögüt, Department of Physical Education and Sports, Faculty of Education, Middle East Technical University, Üniversiteler Mahallesi, Dumlupınar Bulvarı No:1 06800 Çankaya Ankara, Turkey, e-mail: msogut@metu.edu.tr, https://orcid.org/0000-0003-1826-8235

Received: December 4, 2020

Accepted for publication: April 8, 2021

Citation: Söğüt M, Yapici H, Luz LGO, Giudicelli B, Clemente FM, Doğan AA. Maturity-associated variations in anthropometry, physical fitness, and sport-specific skills among young male and female futsal players. Hum Mov. 2022;23(4):70-76; doi: https://doi.org/10.5114/hm.2022.108321. 
factor in the selection and the development of young talented athletes. For instance, in females, while being a late maturer may provide over-representation in gymnastics and figure skating, it may lead to underrepresentation in tennis and swimming [14].

During the last decades, there has been a growing research interest regarding factors affecting the performance in futsal [15]. In a recent observational study, for example, a relative age effect was reported in a large cohort of Spanish futsal players [16]. Furthermore, other recent studies investigated the sports skills, match activities, and performance variables of both young and professional futsal players [17-19]. However, according to Alvares et al. [20], there is scarce information about the role of puberty in the motor performance of futsal players. Correspondingly, to the best of the authors' knowledge, there is no previous report on the influences of maturity status on the physical and functional characteristics in young futsal players of both genders. Therefore, the purpose of this crosssectional study was to examine the maturity-related variations in anthropometry, physical fitness, and sport-specific skills among young futsal players.

\section{Material and methods}

\section{Participants}

Overall, 77 (44 boys and 33 girls) young, aged 10.5$13.7(12.3 \pm 0.9)$ years, futsal players participating in school-based competitions were recruited in the study. They were included in accordance with the following criteria: (i) at least 2 years of experience in futsal training and (ii) at least 3 training sessions per week.

\section{Measurements}

\section{Anthropometric measurements}

A portable stadiometer (Seca 213, Hamburg, Germany) was used to measure sitting and standing height to the nearest $0.1 \mathrm{~cm}$. A digital weighing scale was utilized to evaluate the body mass to the nearest $0.1 \mathrm{~kg}$. A calliper (Holtain Ltd, Crymych, UK) served to assess triceps and medial calf skinfolds to the nearest $0.2 \mathrm{~mm}$. Percentage of body fat (BF\%) was determined with the equations of Slaughter et al. [21]. The maturity status of the players was estimated by the percentage of predicted adult stature (PAS\%) attained at the time of observation [22]. The maturity status of each player was categorized on the basis of their z-score for PAS\%. Subsequently, the participants' maturation was clas- sified as early (z-score $>0.5)$, on-time (z-score \pm 0.5$)$, and late (z-score $<0.5)$.

\section{Grip strength}

A digital hand dynamometer (TKK-5401 Grip-D, Takei, Japan) was utilized to measure the grip strength of the players. They were asked to squeeze the dynamometer, adjusted to their hand size, as hard as possible for 3 seconds. The best of the 3 trials was recorded.

\section{Countermovement jump}

A contact mat (SmartJump, Fusion Sport, Australia) was used to evaluate the vertical jump height. The participants started the test in a standing position. They were asked to keep their hands on the hips. After an immediate downward movement, they performed a take-off to jump the maximal height. The highest value of 2 trials was recorded. The players were instructed for the technical criteria to properly execute the jump. A non-recorded trial was conducted to ensure that the correct movement was performed. The observer provided corrective feedback if necessary.

\section{5 change of direction test}

The participants were asked to run from a 15-m marker toward a line and through 5-m markers, turn on the line, and run back through the 5-m markers $[23,24]$. The time spent in the $10 \mathrm{~m}$ was measured by electronic timing gates (Smartspeed, Fusion Sport, Australia). The faster value of 2 trials was noted.

\section{Ball control}

The ball control test was administered within a $9 \times 9 \mathrm{~m}$ square. The players were asked to keep the ball in the air without using their hands or arms. The numbers of successful hits were recorded. The counting ended when a player moved out of the square or touched the ball with the hands or arms, or the ball hit the floor [25]. The highest value of 2 trials was recorded.

\section{Dribbling}

The dribbling skills of the participants were assessed by the slalom dribble test [26]. The test requires a player to navigate a ball around 9 cones ( $2 \mathrm{~m}$ apart) and return to the starting line as fast as possible. The dribbling performances were measured by an elec- 
tronic timing gate (Smartspeed, Fusion Sport, Australia). The better of 2 attempts was recorded.

\section{Statistical analysis}

The normality of the data was verified with the Shapiro-Wilk test and the variables of age, $\mathrm{PAS} \%, \mathrm{BF} \%$, handgrip, vertical jump, and agility presented normality problems. Attempts to normalize the data were unsuccessful. In addition, the distribution of participants in maturity groups resulted in a low number of members in each group. Consequently, the choice of tests for inferential analyses considered the presented condition. Gender differences were analysed by means of Mann-Whitney $U$ tests. The Kruskal-Wallis test was used to examine maturity status differences in the study variables of boys and girls separately. Betweengroup differences were analysed with a pairwise comparison, with the Bonferroni correction for multiple tests, as post-hoc tests. Subsequently, partial correlations, with age control and with $95 \%$ bias corrected, and accelerated confidence limits based on 1000 bootstrap samples [27], were performed between the PAS\% and the dependent variables. All procedures were carried out by using the SPSS (v. 22.0) software, with a significance level of $\alpha=0.05$.

\section{Ethical approval}

The research related to human use has complied with all the relevant national regulations and institutional policies, has followed the tenets of the Declaration of Helsinki, and has been approved by the Noninterventional Research Ethics Board of Kırıkkale University (No. 2020.06.20).

\section{Informed consent}

Informed consent has been obtained from all individuals included in this study and their parents.

\section{Results}

The descriptive statistics of boys and girls and gender differences are presented in Table 1. Compared with boys, girls were found to be significantly more advanced in maturation and to have greater values of body mass index (BMI) and BF\%. In turn, except for the countermovement jump test, boys outperformed girls in terms of all fitness and sport-skill assessments.

The descriptive statistics of boys in different maturity groups and the results of the Kruskal-Wallis test and partial correlations (controlling for chronological age) are given in Table 2. The Kruskal-Wallis test revealed that early maturing boys were significantly older, more advanced in maturation, and taller than their on-time and late maturing counterparts. They had also higher values in body mass and $\mathrm{BF} \%$, and greater scores in grip strength than late maturing boys. None of the other physical fitness or sport-specific skill measures differed significantly between contrasting maturity groups. Partial correlation results indicated moderate to high correlations between PAS\% and stature, as well as between body mass and grip strength, and a week correlation between PAS\% and $\mathrm{BF} \%$, variables in which early maturing athletes scored significantly higher than their peers, which suggests a relevant effect of somatic maturation on these variables. Other physical fitness and sport-specific skill measures did not show a significant correlation with PAS\%.

Table 1. Descriptive statistics of boys and girls and gender differences

\begin{tabular}{lcccc}
\hline Variables & Boys $(n=44)$ & Girls $(n=33)$ & $U$ & $p$ \\
\hline Chronological age (years) & $12.5(0.8)$ & $12.2(0.9)$ & 584.0 & 0.143 \\
PAS\% & $84.5(4.2)$ & $86.9(4.4)$ & 485.5 & 0.013 \\
Anthropometry & & & & \\
$\quad$ Stature (cm) & $157.8(10.6)$ & $156.5(9.2)$ & 704.5 & 0.825 \\
$\quad$ Body mass (kg) & $45.4(9.9)$ & $49.0(10.1)$ & 545.5 & 0.063 \\
$\quad$ Body mass index $\left(\mathrm{kg} / \mathrm{m}^{2}\right)$ & $18.1(2.4)$ & $19.9(2.9)$ & 462.0 & 0.007 \\
$\quad$ Body fat percentage (\%) & $17.5(1.9)$ & $22.7(5.1)$ & 254.5 & 0.001 \\
Fitness & & & & \\
$\quad$ Grip strength (kg) & $24.0(6.0)$ & $20.4(4.6)$ & 490.5 & 0.015 \\
Vertical jump (cm) & $25.5(3.4)$ & $25.7(7.1)$ & 685.5 & 0.677 \\
505 COD (s) & $3.7(0.3)$ & $3.9(0.3)$ & 372.0 & 0.001 \\
Sports skills & & & & \\
$\quad$ Dribbling (s) & $21.1(1.4)$ & $24.4(2.5)$ & 174.0 & 0.001 \\
$\quad$ Ball control $(n)$ & $38.0(9.6)$ & $16.1(6.3)$ & 25.0 & 0.001 \\
\hline
\end{tabular}

PAS $\%$ - percentage of predicted adult stature, COD - change of direction 
Table 2. Descriptive statistics of boys by maturity status and the results of Kruskal-Wallis test, post-hoc comparisons, and partial correlations, with 95\% bias corrected and accelerated confidence limits based on 1000 bootstrap samples, between maturation and dependent variables, controlling for chronological age

\begin{tabular}{|c|c|c|c|c|c|c|c|}
\hline \multirow{3}{*}{ Dependent variables } & \multicolumn{3}{|c|}{ Maturity groups } & \multicolumn{2}{|c|}{ Kruskal-Wallis } & \multirow{3}{*}{$\begin{array}{c}\text { Post-hoc } \\
\text { comparisons }\end{array}$} & $\begin{array}{c}\text { Correlations: } \\
X_{\mathrm{i}}-Y_{\mathrm{i}}, \mathrm{X}_{\mathrm{i}}-Z_{\mathrm{i}}, \mathrm{X}_{\mathrm{i}}-\mathrm{W}_{\mathrm{i}}\end{array}$ \\
\hline & \multirow{2}{*}{$\begin{array}{c}\text { Early } \\
(n=15)\end{array}$} & \multirow{2}{*}{$\begin{array}{l}\text { On-time } \\
(n=16)\end{array}$} & \multirow{2}{*}{$\begin{array}{c}\text { Late } \\
(n=13)\end{array}$} & \multirow{2}{*}{ Value } & \multirow{2}{*}{$p$} & & $\mathrm{X}_{\mathrm{i}}$ : Maturation \\
\hline & & & & & & & Coefficient (95\% CL) \\
\hline Chronological age (years) & $13.4(0.3)$ & $12.5(0.4)$ & $11.5(0.6)$ & 32.391 & $<0.001$ & Early $>$ on-time $>$ late & - \\
\hline PAS $\%$ & $89.1(1.7)$ & $84.3(1.1)$ & $79.3(2.1)$ & 38.367 & $<0.001$ & Early $>$ on-time $>$ late & - \\
\hline \multicolumn{8}{|l|}{$Y_{i}:$ Anthropometry } \\
\hline Stature $(\mathrm{cm})$ & $168.3(8.1)$ & $156.4(5.3)$ & $147.6(6.4)$ & 26.299 & $<0.001$ & Early $>$ on-time $>$ late & $0.833(0.679 ; 0.920)$ \\
\hline Body mass (kg) & $53.9(10.9)$ & $43.6(5.2)$ & $37.8(4.5)$ & 21.698 & $<0.001$ & Early \& on-time > late & $0.538(0.313 ; 0.695)$ \\
\hline Body mass index $\left(\mathrm{kg} / \mathrm{m}^{2}\right)$ & $18.9(2.5)$ & $17.9(2.6)$ & $17.3(1.7)$ & 3.428 & 0.180 & - & $-0.042(-0.374 ; 0.287)$ \\
\hline Body fat percentage (\%) & $18.6(1.2)$ & $17.6(2.1)$ & $16.2(2.0)$ & 8.149 & 0.017 & Early $>$ late & $0.391(0.059 ; 0.620)$ \\
\hline \multicolumn{8}{|l|}{$\mathrm{Z}_{\mathrm{i}}:$ Fitness } \\
\hline Grip strength (kg) & $26.7(4.5)$ & $24.0(6.2)$ & $20.9(6.2)$ & 10.675 & 0.005 & Early $>$ late & $0.533(0.252 ; 0.737)$ \\
\hline Vertical jump (cm) & $25.9(3.6)$ & $26.2(3.3)$ & $24.0(3.1)$ & 2.701 & 0.259 & - & $0.117(-0.163 ; 0.415)$ \\
\hline 505 COD (s) & $3.5(0.2)$ & $3.7(0.3)$ & $3.8(0.4)$ & 3.874 & 0.144 & - & $-0.037(-0.360 ; 0.248)$ \\
\hline \multicolumn{8}{|l|}{$\mathrm{W}_{\mathrm{i}}$ : Sports skills } \\
\hline Dribbling (s) & $20.6(1.2)$ & $20.9(1.2)$ & $21.9(1.5)$ & 5.114 & 0.078 & - & $-0.109(-0.387 ; 0.148)$ \\
\hline Ball control $(n)$ & $38.4(11.1)$ & $40.4(10.2)$ & $34.6(5.8)$ & 1.886 & 0.390 & - & $0.055(-0.246 ; 0.342)$ \\
\hline
\end{tabular}

95\% CL - BCa (bias-corrected and accelerated) bootstrap 95\% confident limits

PAS $\%$ - percentage of predicted adult stature, COD - change of direction

Table 3. Descriptive statistics of girls by maturity status and the results of Kruskal-Wallis test, post-hoc comparisons, and partial correlations, with 95\% bias corrected and accelerated confidence limits based on 1000 bootstrap samples, between maturation and dependent variables, controlling for chronological age

\begin{tabular}{|c|c|c|c|c|c|c|c|}
\hline \multirow{3}{*}{ Dependent variables } & \multicolumn{3}{|c|}{ Maturity groups } & \multicolumn{2}{|c|}{ Kruskal-Wallis } & \multirow{3}{*}{$\begin{array}{c}\text { Post-hoc } \\
\text { comparisons }\end{array}$} & $\begin{array}{c}\text { Correlations: } \\
\mathrm{X}_{\mathrm{i}}-Y_{\mathrm{i}}, \mathrm{X}_{\mathrm{i}}-Z_{\mathrm{i}}, \mathrm{X}_{\mathrm{i}}-\mathrm{W}_{\mathrm{i}}\end{array}$ \\
\hline & \multirow{2}{*}{$\begin{array}{c}\text { Early } \\
(n=14)\end{array}$} & \multirow{2}{*}{$\begin{array}{l}\text { On-time } \\
(n=10)\end{array}$} & \multirow{2}{*}{$\begin{array}{l}\text { Late } \\
(n=9)\end{array}$} & \multirow{2}{*}{ Value } & \multirow{2}{*}{$p$} & & $\mathrm{X}_{\mathrm{i}}$ : Maturation \\
\hline & & & & & & & Coefficient (95\% CL) \\
\hline Chronological age (years) & $12.9(0.3)$ & $12.1(0.6)$ & $11.1(0.4)$ & 23.165 & $<0.001$ & Early $>$ on-time \& late & - \\
\hline $\mathrm{PAS} \%$ & $90.7(1.1)$ & $87.0(1.5)$ & $80.8(2.2)$ & 28.236 & $<0.001$ & Early > on-time \& late & - \\
\hline \multicolumn{8}{|l|}{$\mathrm{Y}_{\mathrm{i}}$ : Anthropometry } \\
\hline Stature $(\mathrm{cm})$ & $163.7(4.4)$ & $157.3(4.1)$ & $144.2(4.9)$ & 24.847 & $<0.001$ & Early $>$ on-time $\&$ late & $0.849(0.691 ; 0.936)$ \\
\hline Body mass (kg) & $57.7(5.9)$ & $46.4(5.9)$ & $38.5(7.1)$ & 21.117 & $<0.001$ & Early > on-time \& late & $0.487(0.197 ; 0.727)$ \\
\hline Body mass index $\left(\mathrm{kg} / \mathrm{m}^{2}\right)$ & $21.6(2.6)$ & $18.7(2.3)$ & $18.5(2.9)$ & 8.318 & 0.016 & Early $>$ on-time & $0.140(-0.198 ; 0.448)$ \\
\hline Body fat percentage (\%) & $25.6(5.0)$ & $21.4(3.3)$ & $19.5(4.8)$ & 9.318 & 0.009 & Early > late & $0.151(-0.283 ; 0.546)$ \\
\hline \multicolumn{8}{|l|}{$\mathrm{Z}_{\mathrm{i}}:$ Fitness } \\
\hline Grip strength $(\mathrm{kg})$ & $23.4(2.9)$ & $20.7(4.5)$ & $15.5(2.4)$ & 16.297 & $<0.001$ & Early \& on-time > late & $-0.090(-0.489 ; 0.310)$ \\
\hline Vertical jump (cm) & $30.1(6.7)$ & $25.0(6.2)$ & $19.7(3.1)$ & 11.485 & 0.003 & Early $>$ late & $-0.024(-0.307 ; 0.313)$ \\
\hline 505 COD (s) & $3.8(0.2)$ & $3.9(0.3)$ & $4.2(0.2)$ & 13.621 & 0.001 & Early $<$ late & $-0.061(-0.387 ; 0.239)$ \\
\hline \multicolumn{8}{|l|}{$\mathrm{W}_{\mathrm{i}}:$ Sports skills } \\
\hline Dribbling (s) & $22.9(1.9)$ & $24.5(2.4)$ & $26.6(1.5)$ & 13.342 & 0.001 & Early $<$ late & $-0.327(-0.554 ;-0.092)$ \\
\hline Ball control $(n)$ & $18.3(6.3)$ & $16.1(6.3)$ & $12.8(5.2)$ & 4.860 & 0.088 & - & $0.039(-0.324 ; 0.371)$ \\
\hline
\end{tabular}

95\% CL - BCa (bias-corrected and accelerated) bootstrap 95\% confident limits

$\mathrm{PAS} \%$ - percentage of predicted adult stature, COD - change of direction 
The descriptive statistics of girls in different maturity groups and the results of the Kruskal-Wallis test and partial correlations (controlling for chronological age) are given in Table 3. The Kruskal-Wallis test showed that early maturing girls had significantly greater values of all anthropometric measures, except for BMI, and exhibited better performances on all fitness tests than late maturing girls. Moreover, they achieved significantly better results in the dribbling skill test than late maturing girls. Furthermore, they were significantly taller, heavier, and had a higher BMI value than on-time maturing girls. There were no significant differences between early and on-time maturing girls in terms of functional or sports skill tests. No significant differences were observed between ontime and late maturing girls in sports skill measures. On-time maturing girls exhibited better performances in grip strength than late maturing girls. However, PAS\% correlated significantly only with stature (high positive correlation), body mass (moderate positive correlation), and dribbling (weak negative correlation).

\section{Discussion}

The aim of the study was to determine the maturityrelated variations in morphological characteristics and functional capacities in young male and female futsal players. The results revealed that, regardless of gender, early maturing players were significantly taller and heavier. Supportively, when chronological age was controlled as a covariate, partial correlation results indicated moderate to high correlations between the maturation indicator and stature and body mass in both boys and girls. Similar results were also observed in a non-athletic [28] and athletic [29, 30] population. In addition, findings of previous research conducted in young soccer players showed significantly higher values for anthropometrics among early maturers [31, 32]. The increase in body size during puberty is primarily due to changes in hormonal activity [33].

The results demonstrated that, except for grip strength (moderate correlation) in boys, there were no significant associations between maturity status and physical fitness scores in either male or female players. According to Figueiredo et al. [34], variations in functional capacities of young soccer players may not be explained only by biological maturation but also by such predictors as chronological age, experience, and the test items administered. The result regarding the grip strength is in line with the findings of earlier examinations [35, 36]. Greater values obtained by early maturing boys might be attributed to the level of serum testosterone and the body size [33, 37].

The correlation results indicated, except for the dribbling test (weak correlation) in girls, no significant relationships between maturity status and sport-specific skills in either gender. This result is in line with the findings of the previous studies in young soccer players [31, 32, 38]. As noted by several authors [39-40], in addition to maturity status, other factors such as chronological age, body composition, experience, and regular training also have effects on sport-specific skills.

The results revealed that, compared with boys, girls were significantly more advanced in maturation and had greater $\mathrm{BMI}$ and $\mathrm{BF} \%$ values. Conversely, except for the countermovement jump result, boys outperformed girls in terms of all fitness and sport-skill assessments. In a recent investigation, supportive observations were reported for semiprofessional futsal players [41]. However, the paucity of data on the gender effect in young futsal players prohibits the explanation of this finding. Nevertheless, similar results were noted for young soccer players [42, 43].

\section{Conclusions}

This study is original in the sense that it provides data on various morphological and performance characteristics for both male and female young futsal players. The results highlight that rather than with functional and sport-specific features, physical maturity status may be associated with greater body size among futsal players aged 10-14. It must be taken into account that the present study is limited with a relatively small sample size. Therefore, it is recommended for future research to extend the observation in a large sample of young futsal players.

\section{Disclosure statement}

No author has any financial interest or received any financial benefit from this research.

\section{Conflict of interest}

The authors state no conflict of interest.

\section{References}

1. Baxter-Jones AD, Eisenmann JC, Sherar LB. Controlling for maturation in pediatric exercise science. Pediatr Exerc Sci. 2005;17(1):18-30; doi: 10.1123/pes.17.1.18.

2. Malina RM, Rogol AD, Cumming SP, Coelho e Silva MJ, Figueiredo AJ. Biological maturation of youth athletes: assessment and implications. Br J Sports Med. 2015; 49(13):852-859; doi: 10.1136/bjsports-2015-094623. 
3. Georgopoulos NA, Markou KB, Theodoropoulou A, Vagenakis GA, Mylonas P, Vagenakis AG. Growth, pubertal development, skeletal maturation and bone mass acquisition in athletes. Hormones. 2004;3(4):233-243; doi: 10.14310/horm.2002.11132.

4. Baxter-Jones AD, Maffulli N, Mirwald RL. Does elite competition inhibit growth and delay maturation in some gymnasts? Probably not. Pediatr Exerc Sci. 2003;15(4): 373-382; doi: 10.1123/pes.15.4.373.

5. Cumming SP, Standage M, Gillison FB, Dompier TP, Malina RM. Biological maturity status, body size, and exercise behaviour in British youth: a pilot study. J Sports Sci. 2009;27(7):677-686; doi: 10.1080/02640 410902725590.

6. Lloyd RS, Oliver JL, Faigenbaum AD, Myer GD, De Ste Croix MBA. Chronological age vs. biological maturation: implications for exercise programming in youth. J Strength Cond Res. 2014;28(5):1454-1464; doi: 10.1519/JSC.0000000000000391.

7. Söğüt M. Bio-banding in sport [in Turkish]. Turk J Sports Med. 2019;54(2):143-147; doi: 10.5152/tjsm. 2019.126.

8. Rommers N, Mostaert M, Goossens L, Vaeyens R, Witvrouw E, Lenoir M, et al. Age and maturity related differences in motor coordination among male elite youth soccer players. J Sports Sci. 2019;37(2):196-203; doi: 10.1080/02640414.2018.1488454.

9. Söğüt M, Luz LGO, Kaya ÖB, Altunsoy K, Doğan AA, Kirazci S, et al. Age- and maturity-related variations in morphology, body composition, and motor fitness among young female tennis players. Int J Environ Res Public Health. 2019;16(13):2412; doi: 10.3390/ijerph16132412.

10. Till K, Cobley S, O’Hara J, Cooke C, Chapman C. Considering maturation status and relative age in the longitudinal evaluation of junior rugby league players. Scand J Med Sci Sports. 2014;24(3):569-576; doi: 10.1111/ sms.12033.

11. Torres-Unda J, Zarrazquin I, Gil J, Ruiz F, Irazusta A, Kortajarena M, et al. Anthropometric, physiological and maturational characteristics in selected elite and non-elite male adolescent basketball players. J Sports Sci.2013;31(2):196-203; doi:10.1080/02640414.2012. 725133.

12. Kramer T, Huijgen BCH, Elferink-Gemser MT, Visscher C. Prediction of tennis performance in junior elite tennis players. J Sports Sci Med. 2017;16(1):14-21.

13. Söğüt M, Luz LGO, Kaya ÖB, Altunsoy K. Ranking in young tennis players - a study to determine possible correlates. Ger J Exerc Sport Res. 2019;49(3):325-331; doi: 10.1007/s12662-019-00580-7.

14. Cumming SP, Lloyd RS, Oliver JL, Eisenmann JC, Malina RM. Bio-banding in sport: applications to competition, talent identification, and strength and conditioning of youth athletes. Strength Cond J. 2017;39(2): 34-47; doi: 10.1519/SSC.0000000000000281.

15. Dal Pupo J, Barth J, Moura FA, Detanico D. Physical capacities related to running performance during simu- lated matches in young futsal players. Sport Sci Health. 2020;16(4):661-667; doi: 10.1007/s11332-020-00639-1.

16. Lago-Fuentes C, Rey E, Padrón-Cabo A, Prieto-Troncoso J, Garcia-Núñez J. The relative age effect in professional futsal players. J Hum Kinet. 2020;72(1):173183; doi: 10.2478/hukin-2019-0105.

17. Szwarc A, Oszmaniec M. A model of the efficiency of goalkeepers' actions in futsal. Hum Mov. 2020;21(4): 44-53; doi: 10.5114/hm.2020.95990.

18. Ribeiro JN, Gonçalves B, Coutinho D, Brito J, Sampaio J, Travassos B. Activity profile and physical performance of match play in elite futsal players. Front Psychol. 2020;11:1709; doi: 10.3389/fpsyg.2020.01709.

19. Pazetto NF, Mafra Gaino JG, dos Santos CD, de Oliveira Spinosa RM, de Santo DL, Marques I. Comparison of the pass skill between professional and U-15 futsal players under different organization contexts. Hum Mov. 2020;21(2):58-63; doi: 10.5114/hm.2020.89915.

20. Alvares PD, Chaves PJ, de Oliveira Junior MNS, Banja Fernandes TL, Veneroso CE, Torres Cabido CE. Effects of puberty on jump and sprint performance in young futsal players. Rev Bras Med Esporte. 2020;26(2):167171; doi: 10.1590/1517-869220202602215518.

21. Slaughter MH, Lohman TG, Boileau RA, Horswill CA, Stillman RJ, Van Loan MD, et al. Skinfold equations for estimation of body fatness in children and youth. Hum Biol. 1988;60(5):709-723.

22. Khamis HJ, Roche AF. Predicting adult stature without using skeletal age: the Khamis-Roche method. Pediatrics. 1994;94(4 Pt 1):504-507.

23. Vilaça Maio Alves JM, Rebelo AN, Abrantes C, Sampaio J. Short-term effects of complex and contrast training in soccer players' vertical jump, sprint, and agility abilities. J Strength Cond Res. 2010;24(4):936-941; doi: 10.1519/JSC.0b013e3181c7c5fd.

24. Hoare DG, Warr CR. Talent identification and women's soccer: an Australian experience. J Sports Sci. 2000;18(9):751-758; doi:10.1080/02640410050120122.

25. Malina RM, Cumming SP, Kontos AP, Eisenmann JC, Ribeiro B, Aroso J. Maturity-associated variation in sport-specific skills of youth soccer players aged 13-15 years. J Sports Sci. 2005;23(5):515-522; doi: 10.1080/ 02640410410001729928.

26. Vaeyens R, Malina RM, Janssens M, Van Renterghem B, Bourgois J, Vrijens J, et al. A multidisciplinary selection model for youth soccer: the Ghent Youth Soccer Project. Br J Sports Med. 2006;40(11):928-934; doi: 10.1136/ bjsm.2006.029652.

27. Field A. Discovering statistics using IBM SPSS Statistics, $5^{\text {th }}$ ed. Newbury Park: SAGE Publications Ltd.; 2017.

28. Drenowatz C, Eisenmann JC, Pfeiffer KA, Wickel EE, Gentile D, Walsh D. Maturity-related differences in physical activity among 10 - to 12 -year-old girls. Am J Hum Biol. 2010;22(1):18-22; doi: 10.1002/ajhb.20905.

29. Coelho E Silva MJ, Figueiredo AJ, Moreira Carvalho H, Malina RM. Functional capacities and sport-specific skills of 14- to 15-year-old male basketball players: size 
and maturity effects. Eur J Sport Sci. 2008;8(5):277285; doi: 10.1080/17461390802117177.

30. Matthys SPJ, Vaeyens R, Coelho E Silva MJ, Lenoir M, Philippaerts R. The contribution of growth and maturation in the functional capacity and skill performance of male adolescent handball players. Int J Sports Med. 2012;33(7):543-549; doi: 10.1055/s-0031-1298000.

31. Figueiredo AJ, Gonçalves CE, Coelho E Silva MJ, Malina RM. Youth soccer players, 11-14 years: maturity, size, function, skill and goal orientation. Ann Hum Biol. 2009;36(1):60-73; doi: 10.1080/030144608025 70584.

32. Gouvea M, Cyrino ES, Ribeiro AS, da Silva DRP, Ohara D, Valente-Dos-Santos J, et al. Influence of skeletal maturity on size, function and sport-specific technical skills in youth soccer players. Int J Sports Med. 2016; 37(6):464-469; doi: 10.1055/s-0035-1569370.

33. Pearson DT, Naughton GA, Torode M. Predictability of physiological testing and the role of maturation in talent identification for adolescent team sports. J Sci Med Sport. 2006;9(4):277-287; doi: 10.1016/j.jsams.2006. 05.020 .

34. Figueiredo AJ, Coelho e Silva MJ, Malina RM. Predictors of functional capacity and skill in youth soccer players. Scand J Med Sci Sports. 2011;21(3):446-454; doi: 10.1111/j.1600-0838.2009.01056.x.

35. Giudicelli BB, Luz LGO, Sögüt M, Massart AG, Júnior AC, Figueiredo AJ. Bio-banding in judo: the mediation role of anthropometric variables on the maturation effect. Int J Environ Res Public Health. 2020;17(1):361; doi: 10.3390/ijerph17010361.

36. Guimarães E, Baxter-Jones A, Maia J, Fonseca P, Santos A, Santos E, et al. The roles of growth, maturation, physical fitness, and technical skills on selection for a Portuguese under-14 years basketball team. Sports. 2019;7(3):61; doi: 10.3390/sports7030061.

37. Beunen G, Thomis M. Muscular strength development in children and adolescents. Pediatr Exerc Sci. 2000; 12(2):174-197; doi: 10.1123/pes.12.2.174.

38. Figueiredo AJ, Coelho E Silva MJ, Cumming SP, Malina RM. Size and maturity mismatch in youth soccer players 11- to 14-years-old. Pediatr Exerc Sci. 2010;22(4): 596-612; doi: 10.1123/pes.22.4.596.

39. De Oliveira Matta M, Barata Figueiredo AJ, Garcia ES, Werneck FZ, Seabra A. Morphological and maturational predictors of technical performance in young soccer players. Motriz Rev Educ Fis. 2014;20(3):280285; doi: 10.1590/S1980-65742014000300006.

40. Meylan C, Cronin J, Oliver J, Hughes M. Talent identification in soccer: the role of maturity status on physical, physiological and technical characteristics. Int J Sports Sci Coach. 2010;5(4):571-592; doi: 10.1260/ 1747-9541.5.4.571.

41. Lago-Fuentes C, Pérez-Celada S, Prieto-Troncoso J, Rey E, Mecías-Calvo M. Anthropometric and conditional profile in semiprofessional futsal players: differences between sexes. A case study. Rev Int Cienc De- porte. 2020;16(61):330-341; doi: 10.5232/ricyde2020. 06107.

42. O’Brien-Smith J, Bennett KJM, Fransen J, Smith MR. Same or different? A comparison of anthropometry, physical fitness and perceptual motor characteristics in male and female youth soccer players. Sci Med Football. 2020;4(1):37-44; doi: 10.1080/24733938.2019. 1650197.

43. Perroni F, Gallotta MC, Pisano S, Machado Reis V, Emerenziani GP, Guidetti L, et al. Gender differences in anthropometric parameters and technical performance of youth soccer players. Sport Sci Health. 2018;14(2): 399-405; doi: 10.1007/s11332-018-0456-z. 